\title{
Rapid deployment or sutureless versus conventional bioprosthetic aortic valve replacement: A meta-analysis
}

Suk Ho Sohn, MD, ${ }^{a}$ Myoung-jin Jang, PhD, ${ }^{b}$ Ho Young Hwang, MD, PhD, ${ }^{a}$ and Kyung Hwan Kim, MD, $\mathrm{PhD}^{\mathrm{a}}$

\section{ABSTRACT}

Objectives: This meta-analysis was conducted to compare the early and follow-up outcomes of aortic valve replacement using rapid deployment or sutureless (RD) valves (RDAVR group) with aortic valve replacement using conventional bioprostheses (CAVR group).

Methods: A literature search of 5 online databases was conducted. The primary outcomes were postoperative complications and the secondary outcomes included the aortic cross-clamp (ACC) and cardiopulmonary bypass (CPB) times and early mortality and all-cause mortality during follow-up.

Results: Twenty-one articles (RDAVR group $=1297$ patients; CAVR group $=1488$ patients) were selected. The pooled analyses showed that the ACC and CPB times were significantly shorter in the RDAVR group than in the CAVR group (mean difference, $-26.34 ; 95 \%$ confidence interval [CI], -31.86 to -20.82 and mean difference, $-25.33 ; 95 \%$ CI, -30.79 to -19.87 , respectively). The pooled risk ratios (RRs) of any paravalvular leak and permanent pacemaker (PPM) insertion were significantly higher in the RDAVR group than in the CAVR group (RR, 2.32; 95\% CI, 1.53-3.51 and RR, 2.08; 95\% CI, 1.49-2.90, respectively). The pooled analysis showed that the risk of a paravalvular leak grade $\geq 2$ in the RDAVR group did not significantly differ between the RDAVR and CAVR groups (RR, 2.05; 95\% CI, 0.71-5.93). The risk of PPM insertion remained significant when only studies reporting adjusted outcomes were pooled. The risks of other postoperative complications, early mortality, and all-cause mortality during follow-up were not significantly different between the RDAVR and CAVR groups.

Conclusions: RDAVR is associated with significantly shorter ACC and CPB times than CAVR, although this difference did not translate into improved postoperative outcomes, early mortality, and all-cause mortality during follow-up. Care might be needed when implanting RD valves because they are associated with a higher incidence of PPM insertion, regardless of the RD valve type. (J Thorac Cardiovasc Surg 2018;155:2402-12)

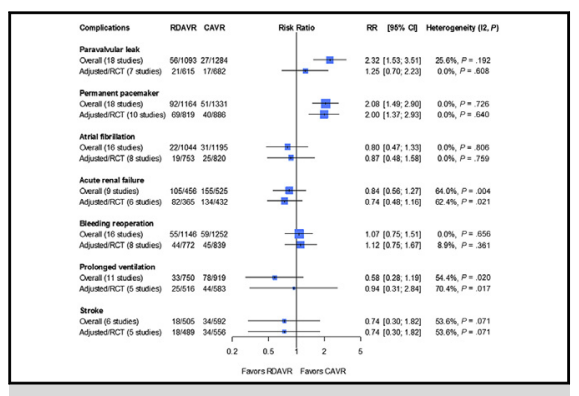

Pooled estimates of postoperative complications between RDAVR and conventional AVR.

\section{Central Message}

Rapid deployment or sutureless AVR is associated with shorter ACC and CPB times without differences in postoperative complications except for a higher occurrence of permanent pacemaker insertion.

\section{Perspective}

This study showed that aortic valve replacement using rapid deployment or sutureless valves was associated with shorter aortic cross-clamp and cardiopulmonary bypass times but also a greater occurrence of permanent pacemaker insertion. Surgeons should carefully select valve types according to the benefit and disadvantage of rapid deployment or sutureless valves and conventional valves.

See Editorial Commentary page 2413.

See Editorial page 2400 .

\footnotetext{
From the ${ }^{\mathrm{a} D e p a r t m e n t}$ of Thoracic and Cardiovascular Surgery, and ${ }^{\mathrm{b}}$ Medical Research Collaborating Center, Seoul National University Hospital, Seoul National University College of Medicine, Seoul, Korea.

Drs Sohn and Jang contributed equally to this work.

Drs Hwang and Kim contributed equally to this work.

Received for publication Sept 17, 2017; revisions received Dec 14, 2017; accepted for publication Jan 11, 2018; available ahead of print March 13, 2018.

Address for reprints: Ho Young Hwang, MD, PhD, Department of Thoracic and Cardiovascular Surgery, Seoul National University Hospital, Seoul National University College of Medicine, 101 Daehak-ro, Jongno-gu, Seoul 03080, Korea (E-mail: scalpel@hanmail.net).

$0022-5223 / \$ 36.00$

Copyright (c) 2018 by The American Association for Thoracic Surgery

https://doi.org/10.1016/j.jtcvs.2018.01.084
}

Despite the development of transcatheter aortic valve implantation (TAVR) for elderly and high-risk patients, surgical aortic valve replacement (AVR) is still considered the treatment of choice for patients with severe aortic

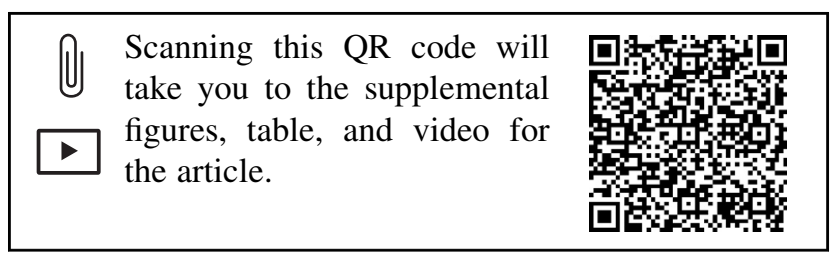




$$
\begin{aligned}
& \text { Abbreviations and Acronyms } \\
& \text { ACC }=\text { aortic cross-clamp } \\
& \text { AVR }=\text { aortic valve replacement } \\
& \text { CAVR }=\text { conventional aortic valve replacement } \\
& \text { CI }=\text { confidence interval } \\
& \text { CPB }=\text { cardiopulmonary bypass } \\
& \text { CV }=\text { conventional valve } \\
& \text { HR }=\text { hazard ratio } \\
& \text { LBB }=\text { left bundle branch } \\
& \text { MD }=\text { mean difference } \\
& \text { MeSH }=\text { medical subject heading } \\
& \text { NRS }=\text { nonrandomized study } \\
& \text { PPM }=\text { permanent pacemaker } \\
& \text { PSM }=\text { propensity score-matching } \\
& \text { PVL } \text { paravalvular leak } \\
& \text { RCT }=\text { randomized controlled trial } \\
& \text { RD }=\text { rapid deployment or sutureless } \\
& \text { RDAVR }=\text { rapid deployment aortic valve } \\
& \text { replacement } \\
& \text { RR }=\text { risk ratio } \\
& \text { ROB }=\text { risk of bias } \\
& \text { TAVR }=\text { transcatheter aortic valve replacement }
\end{aligned}
$$

stenosis. ${ }^{1,2}$ Recently, rapid deployment or sutureless (RD) valves were introduced to overcome the limitations of TAVR as well as conventional surgical AVR. ${ }^{3,4}$ The theoretical advantages of RD valves include a short surgery time, the ease of insertion even in limited operating fields, and their optimal hemodynamic properties. ${ }^{3,5}$ However, whether the RD valves are truly beneficial is controversial. ${ }^{6,7}$ Therefore, this meta-analysis was conducted to compare the early and follow-up outcomes of AVR using RD valves with conventional bioprosthetic AVR.

\section{METHODS}

\section{Data Source and Literature Search}

This systematic review and meta-analysis was conducted according to the Preferred Reporting Items for Systematic Reviews and Meta-Analyses guidelines. ${ }^{8}$ Full-text articles comparing the results of AVR using RD valves (RDAVR group) with those of standard AVR using conventional bioprostheses (CAVR group) were searched in the Medline, Embase, Cochrane Central Register of Controlled Trials, Web of Science, and Scopus databases on May 23, 2017. No restrictions were placed on the language or publication year. The following key words and medical subject heading $(\mathrm{MeSH})$ terms were searched in Medline: (("aortic valve" [MeSH Terms] OR "heart valve prosthesis implantation" [MeSH Terms]) OR (("aortic valve replacement"[Title/Abstract] OR "aortic valve prosthesis"[Title/Abstract]) OR "aortic prosthesis"[Title/ Abstract]) OR "prosthetic aortic valve" [Title/Abstract]) OR "aortic valve implantation" [Title/Abstract])) AND ("sutureless surgical procedures"[MeSH Terms] OR ("sutureless"[Title/Abstract] OR "rapid"[Title/Abstract])). The search strategies for other databases were adapted from this Medline strategy.

\section{Study Selection}

Study selection was independently performed by 2 reviewers (S.H.S. and H.Y.H.) on the basis of predefined selection criteria. Any disagreements between the reviewers were resolved through discussion. The study selection was performed through the following 2 levels of screening: the titles and abstracts of the searched studies were screened at the first level and the full texts were reviewed at the second level. Studies were included if they met the following criteria: (1) enrolled patients who underwent AVR; and (2) compared the clinical outcomes of RDAVR with those of CAVR. When duplicated publications with overlapping study populations were found, the most appropriate article for this comparison was selected on the basis of the confounding bias and the follow-up duration.

\section{Data Extraction}

The study characteristics and the patients' baseline data were extracted independently by 2 reviewers (S.H.S. and H.Y.H.). Data regarding study outcomes were also independently extracted by 2 reviewers (M.-J.J. and H.Y.H.). Any disagreements between reviewers were resolved through discussion by 3 authors (S.H.S., M.-J.J., and H.Y.H.). The corresponding author of 1 of the included studies ${ }^{7}$ was contacted via e-mail to clarify the outcome data.

\section{Quality Assessment}

The overall study quality was assessed independently by 2 reviewers (M.-J.J. and H.Y.H.) using the Cochrane Risk of Bias Tool for randomized controlled trials (RCTs) and the Risk of Bias In Non-Randomized Studies of Interventions for nonrandomized studies (NRSs). ${ }^{9}$ In the Risk Of Bias In Non-randomized Studies of Interventions, 7 domains of risk of bias (ROB) were assessed and the overall ROB was determined to be low, moderate, serious, or critical on the basis of the assessment of each domain. Any disagreements between reviewers were resolved through discussion by 3 authors (S.H.S., M.-J.J., and H.Y.H.).

\section{Statistical Analysis}

The primary outcomes were the incidence of paravalvular leak (PVL), the need for permanent pacemaker (PPM) insertion, and other postoperative complications such as acute renal failure, atrial fibrillation, bleeding reoperation, prolonged ventilation, and stroke. The secondary outcomes included aortic cross-clamp (ACC), cardiopulmonary bypass (CPB) times, mean transvalvular pressure gradient, early mortality, and all-cause mortality during follow-up. For the continuous outcomes, the results were presented as the mean differences (MDs) with $95 \%$ confidence intervals (CIs). For studies that reported median and interquartile or overall ranges, the mean values and standard deviations were estimated using a formula. ${ }^{10}$ Dichotomous outcomes were compared as risk ratios (RRs) with the $95 \%$ CIs. For all-cause mortality during follow-up, the hazard ratios (HRs) and 95\% CIs were extracted directly from the studies or were calculated using other available statistical information (log rank tests or Kaplan-Meier curves). ${ }^{11}$ For studies that only provided the numbers of events, RRs were calculated instead of the HRs. Statistical heterogeneity between the studies was assessed with the $\chi^{2}$ test and the $I^{2}$ statistics. $I^{2}$ values of $25 \%, 50 \%$, and $75 \%$ have been suggested to be indicators of low, moderate, and high heterogeneity, respectively. ${ }^{12} \mathrm{~A}$ random-effects model with the DerSimonian and Laird method was used if substantial heterogeneity was found $\left(I^{2}>50 \%\right)$; otherwise, a fixed effects model was applied using the Mantel-Haenszel and inverse variance methods for binary and continuous outcomes, respectively. For all-cause mortality during follow-up, log-transformed HRs or RRs were pooled using the generic inverse variance method. Overall pooled estimates from all included studies were presented with those according to the type of RD valve, followed by pooled estimates from studies presenting adjusted results and 2 RCTs. 
TABLE 1. Study characteristics

\begin{tabular}{|c|c|c|c|c|c|c|c|c|c|c|}
\hline \multirow[b]{2}{*}{ Study } & \multirow[b]{2}{*}{ Operative era } & \multirow[b]{2}{*}{ Country } & \multirow[b]{2}{*}{$\begin{array}{l}\text { Study } \\
\text { type }\end{array}$} & \multicolumn{3}{|c|}{ Study population } & \multirow[b]{2}{*}{$\begin{array}{c}\text { Type of } \\
\text { RD valve }\end{array}$} & \multicolumn{2}{|c|}{ Clinical follow-up } & \multirow{2}{*}{$\begin{array}{c}\text { Statistical } \\
\text { methods for } \\
\text { adjustment }\end{array}$} \\
\hline & & & & Total & RD & $\mathbf{C V}$ & & $\begin{array}{c}\text { Duration, } \\
\text { years }\end{array}$ & $\begin{array}{c}\text { Completeness, } \\
\%\end{array}$ & \\
\hline 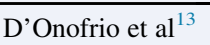 & $2008-2011$ & Italy & NRS & 143 & 31 & 112 & Perceval S & - & - & - \\
\hline Shretha et $\mathrm{al}^{4}$ & $2007-2012$ & Germany & NRS & 120 & 50 & 70 & Perceval S & $2.4 \pm 1.4$ & 95.8 & - \\
\hline Gilmanov et $\mathrm{l}^{14}$ & 2004-2014 & Italy & NRS & 266 & 133 & 133 & Mixed $\dagger$ & $2.9 \pm 2.4$ & - & PSM \\
\hline König et al ${ }^{15}$ & $2012-2013$ & Germany & NRS & 28 & 14 & 14 & Perceval S & - & - & - \\
\hline Pollari et a ${ }^{16}$ & 2010-2013 & Germany & NRS & 164 & 82 & 82 & Perceval S & $1.1 \pm 0.5$ & 100 & PSM \\
\hline Muneretto et al ${ }^{17}$ & $2007-2014$ & Italy and France & NRS & 408 & 204 & 204 & Perceval S & $3.4 \pm 2.3$ & 95.8 & PSM \\
\hline Vola et $\mathrm{al}^{18}$ & 2009-2013 & France & NRS & 83 & 41 & 42 & 3f Enable & $2.1 \pm 1.0$ & - & - \\
\hline Andreas et $\mathrm{al}^{6}$ & $2010-2014$ & Austria & NRS & 248 & 116 & 132 & Intuity & $2.5 \pm 1.3$ & 100 & - \\
\hline Borger et $^{19}{ }^{19}$ & 2012-2013 & Germany & $\mathrm{RCT}$ & 94 & 46 & 48 & Intuity & Up to 1 & 100 & $\mathrm{RCT}$ \\
\hline Bruno et $\mathrm{al}^{20}$ & $2012-2015$ & Italy & NRS & 60 & 30 & 30 & Intuity & - & - & PSM \\
\hline Dalén et $\mathrm{al}^{21}$ & 2005-2014 & Multinational* & NRS & 342 & 171 & 171 & Perceval S & $2.7 \pm 2.1$ & 100 & PSM \\
\hline Dedeilias et $\mathrm{al}^{22}$ & 2012-2014 & Greece & RCT & 50 & 25 & 25 & Perceval S & $0.7 \pm 0.1$ & 100 & RCT \\
\hline Forcillo et $\mathrm{al}^{23}$ & 2011-2015 & Canada & NRS & 195 & 65 & 130 & Perceval S & - & - & PSM \\
\hline Mataraci et a ${ }^{24}$ & 2009-2014 & Turkey & NRS & 46 & 21 & 25 & Mixed $\ddagger$ & - & - & - \\
\hline Shalabi et al ${ }^{5}$ & 2011-2014 & Israel & NRS & 44 & 22 & 22 & Perceval S & $2.5 \pm 1.9$ & 100 & Matching \\
\hline Belluschi et $\mathrm{al}^{25}$ & 2012-2016 & Italy & NRS & 124 & 62 & 62 & Perceval S & - & - & - \\
\hline Bening et $\mathrm{al}^{26}$ & 2013-2015 & Germany & NRS & 68 & 43 & 25 & Intuity & - & - & - \\
\hline Ferrari et $\mathrm{al}^{7}$ & 2014-2015 & Switzerland & NRS & 64 & 32 & 32 & Intuity & Up to 1 & 100 & - \\
\hline Konertz et $\mathrm{al}^{27}$ & 2010-2015 & Germany & NRS & 52 & 16 & 36 & Perceval S & - & - & - \\
\hline Minami et $\mathrm{al}^{28}$ & 2007-2011 & Belgium & NRS & 104 & 52 & 52 & Perceval S & Up to 1 & 100 & - \\
\hline Smith et $\mathrm{al}^{29}$ & $2008-2015$ & Australia & NRS & 82 & 41 & 41 & Mixed $\S$ & - & - & PSM \\
\hline
\end{tabular}

Perceval S valve from Sorin Group (Milan; Italy); Intuity from Edwards Lifescience Corp (Irvine, Calif); and 3f Enable from Medtronic ATS Medical (Minneapolis, Minn). RD, Rapid deployment or sutureless; $C V$, conventional valve; $N R S$, nonrandomized study; $P S M$, propensity score-matching; $R C T$, randomized controlled study. *Sweden, Finland, Italy, Germany, and Belgium. †Perceval S $(\mathrm{n}=125)$ and Intuity $(\mathrm{n}=6)$ and $3 \mathrm{f}$ Enable $(\mathrm{n}=2)$. †PPerceval $\mathrm{S}(\mathrm{n}=17)$ and Intuity $(\mathrm{n}=4)$. §Intuity $(\mathrm{n}=24)$ and $3 \mathrm{f}$ Enable $(\mathrm{n}=27)$.

Meta-regression was performed to explore heterogeneity among the studies. Study characteristics, including the proportion of patients with a minimally invasive approach and the mean ACC and CPB times in the CAVR group, were considered covariates in the meta-regression of the MDs in the ACC and CPB times. A funnel plot and Egger test for asymmetry were applied to assess the possibility of publication bias among the studies. All analyses were performed using STATA version 12.0 (StataCorp, College Station, Tex). Two-sided $P$ values $<.050$ were considered statistically significant.

\section{RESULTS \\ Identification of Studies}

The database searches identified 2046 articles. Among these articles, 2017 publications were excluded, because they clearly did not fulfill the selection criteria on the basis of the title and abstract. Full articles were obtained for the remaining 29 articles. After the scrutiny of these articles, 8 publications were excluded because of unmet inclusion criteria $(n=3)$ or duplicated data $(n=5)$. Therefore, a total of 21 studies were included in this review (Figure E1). ${ }^{4-7,13-29}$

\section{Study Characteristics and Patient Populations}

Among the 21 studies with 2785 patients (RDAVR group $=1297$ patients and CAVR group $=1488$ patients),
2 studies presented the results of RCTs $(n=144)$, and 19 presented the outcomes of NRSs $(n=2641)$. Twelve studies exclusively used the Perceval S (Sorin Group; Milan; Italy), 4,5,13,15-17,21-23,25,27,28 whereas the Edwards Intuity valve (Edwards Lifescience Corp; Irvine, Calif) was used exclusively in 5 studies. ${ }^{6,7,19,20,26}$ A minimally invasive approach through mini-sternotomies or right anterior thoracotomies were more frequently performed in the RDAVR group than in the CAVR group $(69.1 \%$ vs $37.7 \%)$. Clinical follow-up was reported in 12 studies ${ }^{4-7,14,16-19,21,22,28}$ up to an average follow-up duration of 2.9 years (Table 1). On average or median, the patients were in their $70 \mathrm{~s}$, and $59 \%$ of the patients were female (Table 2).

\section{Quality of the Included Studies}

The overall ROB of 2 RCTs $^{19,22}$ was graded as low; for the random number generation and allocation concealment domains, 1 study $^{22}$ used a randomization strategy with a computer-assisted mathematic model and was rated low, whereas the other study ${ }^{19}$ was rated unclear. Neither of these studies reported information on blinding of the participants and personnel or blinding of the outcome 


\begin{tabular}{|c|c|c|c|c|c|c|c|c|c|}
\hline \multirow[b]{2}{*}{ Reference } & \multicolumn{2}{|c|}{ Age, $y$} & \multicolumn{2}{|c|}{ Female sex, \% } & \multicolumn{2}{|c|}{ EuroScore } & \multicolumn{2}{|c|}{$\begin{array}{c}\text { Minimally } \\
\text { invasive } \\
\text { approach }\end{array}$} & \multirow{2}{*}{$\begin{array}{c}\begin{array}{c}\text { Isolated } \\
\text { AVR, \% }\end{array} \\
\text { RD } \\
\text { AVR }\end{array}$} \\
\hline & RD AVR & CAVR & RD AVR & CAVR & RD AVR & CAVR & $\begin{array}{c}\overline{\text { RD AVR, }} \\
\%\end{array}$ & $\begin{array}{c}\text { CAVR, } \\
\%\end{array}$ & \\
\hline D'Onofrio et $^{\prime} \mathbf{l}^{13}$ & \multicolumn{2}{|c|}{$73.5 \pm 12.6$} & 94.2 & & $18.3 \pm 14.6$ & & $40^{*}$ & 0 & 100.0 \\
\hline Shretha et $\mathrm{al}^{4}$ & $79.8 \pm 4.5$ & $77.4 \pm 5.5$ & 94.0 & 94.3 & $20.4 \pm 10.7$ & $16.7 \pm 10.4$ & 72 & 4.3 & 100.0 \\
\hline 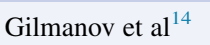 & $75.3(70.1-79.6) \dagger$ & $73.6(68.1-78.7) \dagger$ & 44.4 & 42.9 & $5.83(3.74-8.77) \dagger$ & $5.46(3.53-8.17) \dagger$ & 100 & 100 & 100.0 \\
\hline König et al ${ }^{15}$ & $78 \pm 2.6$ & $74 \pm 4.4$ & 85.7 & 35.7 & $7.4 \pm 1.1$ & $5.9 \pm 2.2$ & 0 & 0 & 82.1 \\
\hline Pollari et al ${ }^{16}$ & $75.5 \pm 5$ & $74.5 \pm 8.1$ & 61.0 & 52.4 & $12.1 \pm 4.9$ & $10.9 \pm 4.2$ & 70 & 75.6 & 80.5 \\
\hline Muneretto et al ${ }^{17}$ & $79 \pm 4$ & $80 \pm 3$ & 51.5 & 48.0 & $18.9 \pm 5.9$ & $19.2 \pm 7.4$ & - & - & 100.0 \\
\hline Vola et al ${ }^{18}$ & $75.7 \pm 6.3$ & $75.3 \pm 6.1$ & 41.5 & 45.2 & $4.5 \pm 3.1$ & $4.1 \pm 2.7$ & 100 & 100 & 100.0 \\
\hline Andreas et $\mathrm{al}^{6}$ & $75 \pm 8$ & $70 \pm 9$ & 61.2 & 31.1 & $9.3 \pm 9.1$ & $9.3 \pm 10.1$ & 59 & 38.7 & 100.0 \\
\hline Borger et al ${ }^{19}$ & $73.0 \pm 5.3$ & $74.2 \pm 5.0$ & 41.3 & 56.3 & $6.4 \pm 3.7$ & $6.7 \pm 3.6$ & 100 & 0 & 100.0 \\
\hline Bruno et $\mathrm{al}^{20}$ & $72.7 \pm 11.4$ & $75.8 \pm 9.6$ & 63.3 & 60.0 & - & - & 100 & 100 & 100.0 \\
\hline Dalén et $\mathrm{al}^{21}$ & $77.3 \pm 5.1$ & $77.4 \pm 6.1$ & 59.6 & 63.2 & $9.8 \pm 5.5$ & $9.6 \pm 6.9$ & 100 & 0 & 100.0 \\
\hline Dedeilias et $\mathrm{al}^{22}$ & $80 \pm 3.3$ & $79 \pm 4.1$ & 60.0 & 44.0 & $9.5 \pm 5.5$ & $9.9 \pm 3.6$ & 0 & 0 & 94.0 \\
\hline Forcillo et $\mathrm{al}^{23}$ & $83 \pm 3$ & $83 \pm 3$ & 20.0 & 53.1 & $4.4(2.8-8.4) \dagger$ & $5.3(3.1-9.0) \dagger$ & $18^{*}$ & $8^{*}$ & 48.7 \\
\hline Mataraci et $\mathrm{al}^{24}$ & $73.0 \pm 8.4$ & $76.2 \pm 6.2$ & 71.4 & 36.0 & $2.8 \pm 1.5$ & $3.4 \pm 2.4$ & 0 & 0 & 58.7 \\
\hline Shalabi et $\mathrm{al}^{5}$ & $77 \pm 6$ & $79 \pm 6$ & 90.9 & 90.9 & $15 \pm 16$ & $14 \pm 16$ & 23 & 0 & 100.0 \\
\hline Belluschi et $\mathrm{al}^{25}$ & $79(75-82) \dagger$ & $79(76-81) \dagger$ & 62.9 & 62.9 & $8.5(6.6-11.1) \dagger$ & $16.0(9.1-27.7) \dagger$ & 65 & 0 & 75.8 \\
\hline Bening et $\mathrm{al}^{26}$ & $74.1 \pm 6.6$ & $74.2 \pm 6.6$ & 37.2 & 32.0 & $5.7(3.9-9.0) \dagger$ & $5.0(3.1-9.1) \dagger$ & 100 & 100 & 100.0 \\
\hline Ferrari et $\mathrm{al}^{7}$ & $78 \pm 5.6$ & $72.5 \pm 6$ & 46.9 & 21.9 & $7.9 \pm 0.06$ & $4.2 \pm 0.03$ & 6.3 & 6.3 & 70.3 \\
\hline Konertz et $\mathrm{al}^{27}$ & $73(58-83) \ddagger$ & $64,35-80 \ddagger$ & 81.3 & 25.0 & - & - & 100 & 100 & 100.0 \\
\hline Minami et $\mathrm{al}^{28}$ & $79.1 \pm 3.5$ & $78.5 \pm 3.5$ & 59.6 & 59.6 & $12.8 \pm 7.8$ & $9.7 \pm 5.5$ & 0 & 17.3 & 57.7 \\
\hline Smith et al ${ }^{29}$ & $76.5 \pm 5.7$ & $75.9 \pm 6.1$ & 51.2 & 58.5 & - & - & 0 & 0 & 48.8 \\
\hline
\end{tabular}

$R D$, Rapid deployment or sutureless; $A V R$, aortic valve replacement; $C A V R$, conventional aortic valve replacement. *Proportion in entire group before matching. $\dagger$ Median with interquartile range. $\ddagger$ Median with range.

assessors. The ROB of both studies was considered low for the other domains. Of the $19 \mathrm{NRSs}, 11$ studies $\mathrm{s}^{4,6,7,13,15,18,24-28}$ were graded as overall severe ROB because of the presence of confounding biases, because the patients' baseline characteristics were not balanced across groups and appropriate adjustments for confounding factors were not used. The other 8 studies used propensity score matching $14,16,17,20,21,23,29$ or $1: 1$ matching $^{5}$ and were rated overall moderate ROB, because the baseline characteristics were similar between groups, and the other ROB items were graded low (Table E1).

\section{ACC and CPB Times}

All of the studies compared the ACC and CPB times between the 2 groups. Pooled analyses revealed that the ACC and CPB times were shorter in the RDAVR than in the CAVR group, with differences of 25 minutes and 26 minutes, respectively (MD, $-26.34 ; 95 \% \mathrm{CI},-31.86$ to $-20.82 ; P<.001$ and $\mathrm{MD},-25.33 ; 95 \% \mathrm{CI},-30.79$ to $-19.87 ; P<.001$, respectively; Figure 1 ). These results were also similar when the ACC and CPB times were compared in the 10 studies showing adjusted results
(MD, $-25.63 ; 95 \% \mathrm{CI},-30.63$ to $-20.63 ; P<.001$ and MD, $-25.33 ; 95 \% \mathrm{CI},-30.79$ to -19.87 , respectively), and in the 15 studies that included only patients who underwent isolated AVR (MD, $-26.48 ; 95 \% \mathrm{CI},-32.74$ to $-20.23 ; P<.001$ and $\mathrm{MD},-24.19 ; 95 \% \mathrm{CI},-30.32$ to -18.05 , respectively). The meta-regression analyses revealed significant contributions of the $\mathrm{ACC}$ and $\mathrm{CPB}$ times in the CAVR group to the high heterogeneity of the MDs of the ACC and CPB times $(P<.001$ in each analysis); the studies with longer mean ACC and CPB times in the CAVR group had greater MDs for the ACC and CPB times, respectively (Figure 2).

\section{Risk of Postoperative Complications: PVL}

A pooled analysis of any PVL from 12 studies with 2377 patients ${ }^{4-7,13,15,17-21,28}$ showed a significantly higher risk of any PVL in the RDAVR group than in the CAVR group (RR, 2.32; 95\% CI, 1.53-3.51; $I^{2}=25.6 \%$; Figure 3 ). The risks of any PVL were insignificant when the pooled estimates were drawn from the adjusted results in 5 studies (RR, 1.25; 95\% CI, 0.70-2.23; $I^{2}=0 \%$; Figure 3). PVLs grade $\geq 2$ (or moderate) were separately reported in 5 


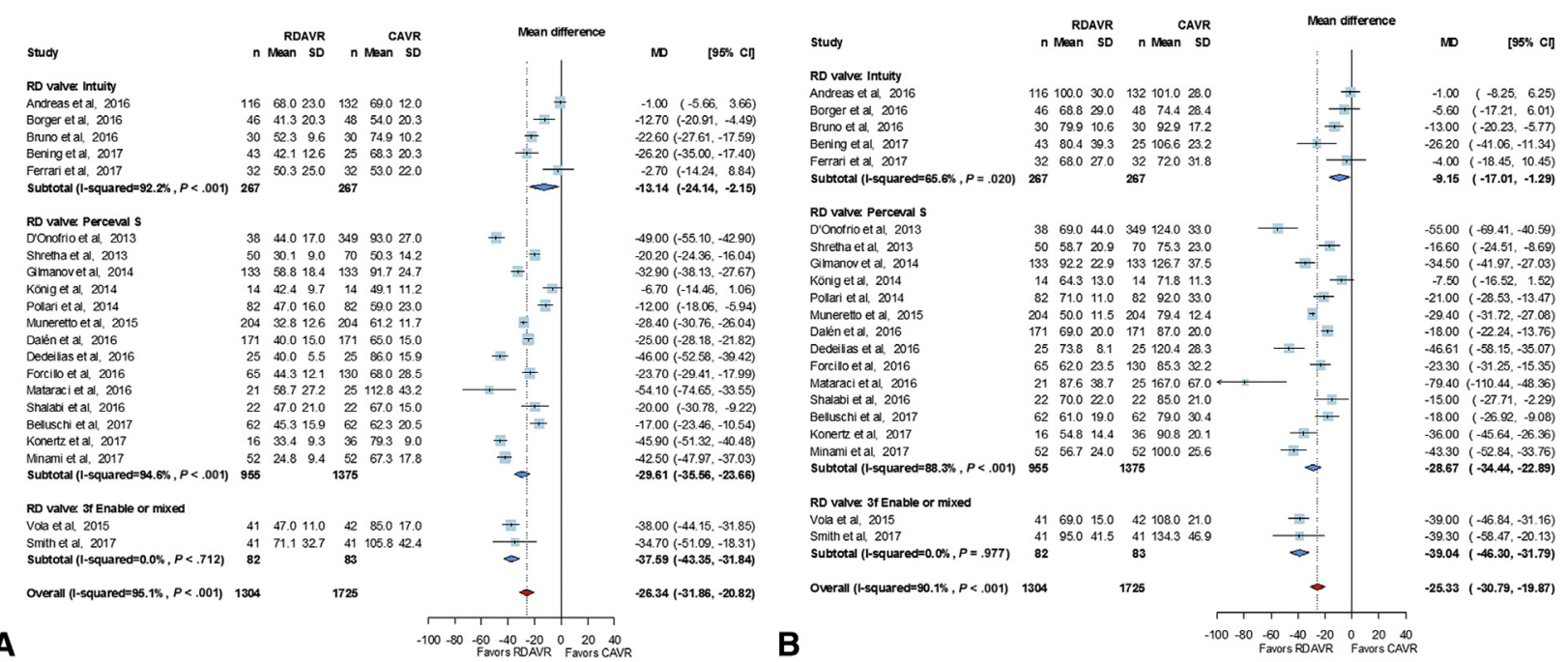

FIGURE 1. Mean difference (MD) of (A) aortic cross clamp (ACC) and (B) cardiopulmonary bypass (CPB) times between rapid deployment (RD) or sutureless aortic valve replacement $(A V R)$ and conventional bioprosthetic AVR (CAVR) groups. $C I$, Confidence interval; $S D$, standard deviation.

studies. $6,7,17,18,21$ The pooled analysis showed that the incidence of a PVL grade $\geq 2$ was not significantly different between the RDAVR and CAVR groups (RR, 2.05; 95\% CI, 0.71-5.93; $I^{2}=0.0 \%$; Figure 3).

\section{Risk of Postoperative Complications: PPM Insertion}

The risk of the need for PPM insertion after AVR was drawn from 17 studies with 2435 patients ${ }^{5-7,13-19,21-23,26-29}$ after the exclusion of 1 study that reported no patients with a PPM insertion. ${ }^{20}$ The pooled analysis showed that the risk of PPM insertion was significantly higher in the RDAVR group than in the CAVR group (RR, 2.08; 95\% CI, $\left.1.49-2.90 ; I^{2}=0 \%\right)$. The risk of PPM was also significant in pooled estimates from the adjusted results from 9 studies (Figure 4).

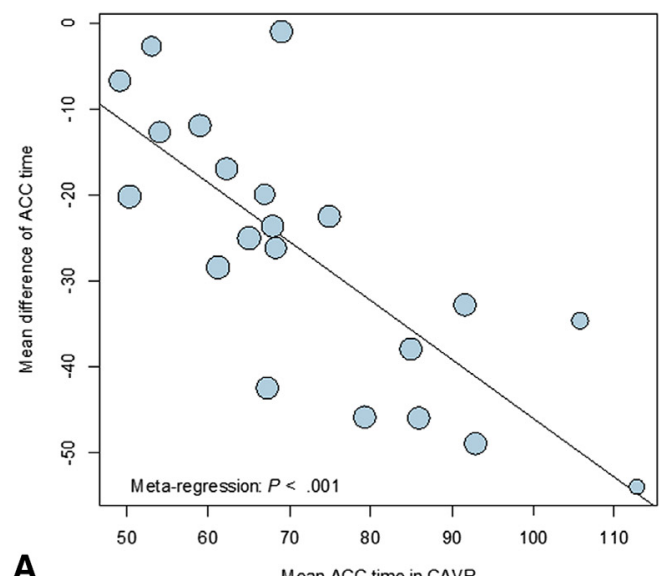

\section{Risks of Other Postoperative Complications}

The risks of acute renal failure, atrial fibrillation, bleeding reoperation, prolonged ventilation, and stroke were reported in 11, , $13,17-21,23,25,28,29_{9,}^{5,7,14,16,20,23,26,29} 16,6^{4,6,7,14-21,23,25-27,29}$ $6^{14,17,19,23,28,30}$ and $16^{5,7,13-21,23,25-28}$ studies, respectively. The pooled analyses showed no significant differences in the risks of postoperative complications between the 2 groups (Figure E2).

\section{Transvalvular Pressure Gradient of Prosthetic Valves}

The transvalvular pressure gradient was presented in 13 studies. ${ }^{4,6,7,13,15,17-20,24,26-28}$ The pooled analyses showed no significant differences in the mean pressure gradient between the 2 groups in the overall (MD, $-1.19 ; 95 \%$

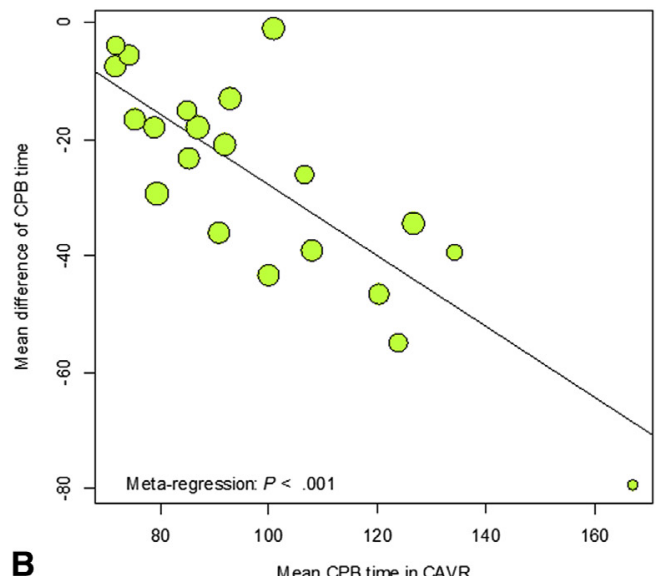

FIGURE 2. Metaregression analyses showed that longer aortic cross clamp ( $A C C)$ and cardiopulmonary bypass $(C P B)$ times in the conventional aortic valve replacement $(C A V R)$ groups were significantly associated with greater mean difference for (A) ACC and (B) CPB times, respectively, between the rapid deployment or sutureless aortic valve replacement groups. 


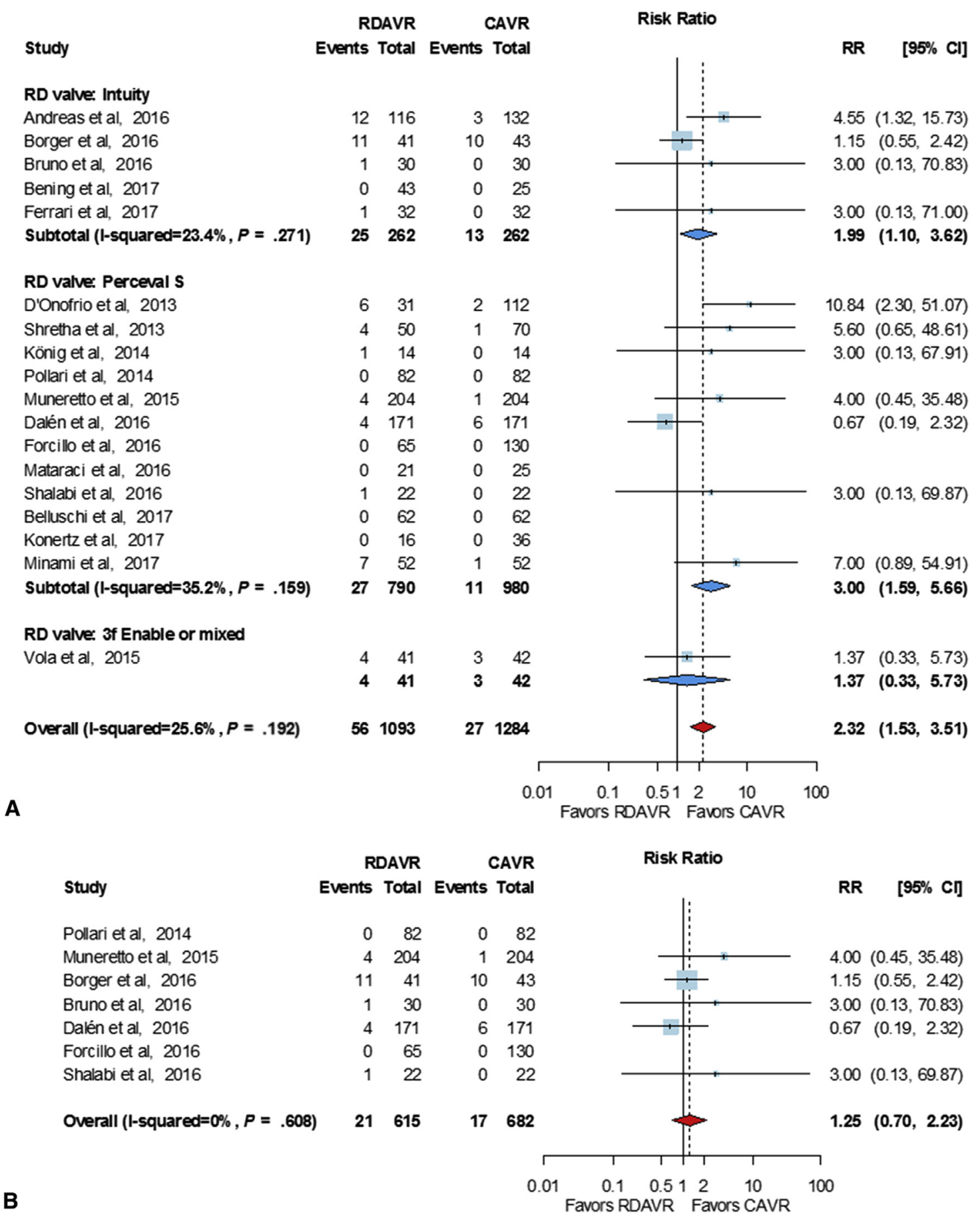

FIGURE 3. Risk ratios (RRs) of any paravalvular leak (PVL) (A) from overall studies and (B) from adjusted or randomized studies. RDAVR, Rapid deployment or sutureless aortic valve replacement; $C A V R$, conventional aortic valve replacement; $R D$, rapid deployment; $C I$, confidence interval.

$\mathrm{CI},-2.49$ to $0.10 \mathrm{~mm} \mathrm{Hg}$ ) and adjusted results ( $\mathrm{MD},-0.83$; $95 \% \mathrm{CI},-1.68$ to $0.02 \mathrm{~mm} \mathrm{Hg}$; Figure E3).

\section{Early Mortality and All-Cause Mortality During Follow-up}

The early mortality rate was reported in all studies except one, ${ }^{22}$ but the RRs could not be calculated for 5 studies in which the early mortality rate was $0 \% \cdot{ }^{5,15,20,27,28}$ Early mortality was defined as 30-day mortality and in-hospital death in 11 and 4 studies, ${ }^{7,14,24,25}$ respectively. The risk of early mortality was not significantly different between the RDAVR and CAVR groups (RR, 0.78; 95\% CI, $\left.0.50-1.22 ; I^{2}=0 \%\right)$. The all-cause mortality during follow-up was also similar between the RDAVR and 


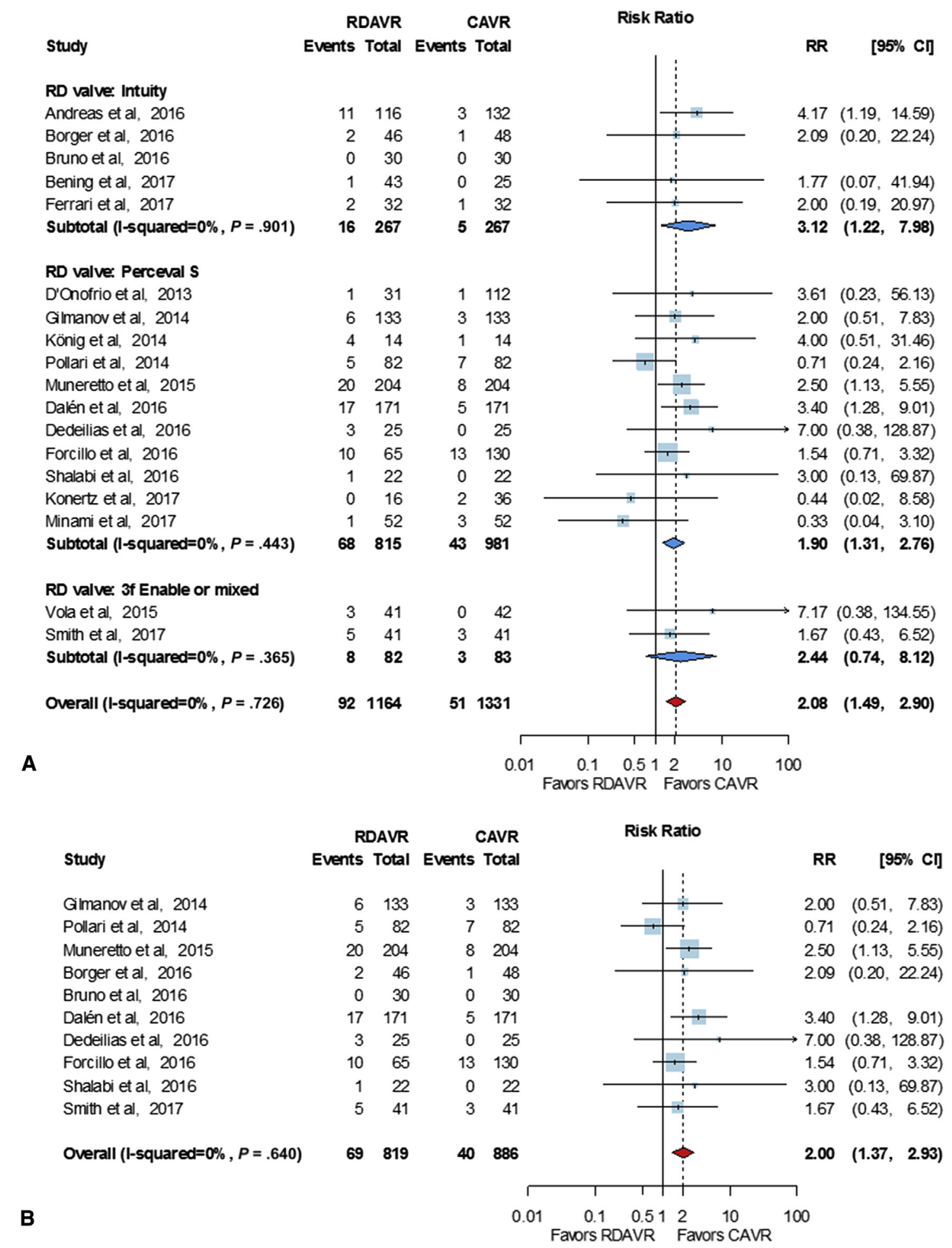

FIGURE 4. Risk ratio $(R R)$ of permanent pacemaker implantation after rapid deployment or sutureless aortic valve replacement $(R D A V R)$ and conventional bioprosthetic aortic valve replacement $(C A V R)(\mathrm{A})$ from overall studies and (B) from adjusted or randomized studies. $C I$, Confidence interval; $R D$, rapid deployment.

CAVR groups; the HR from 6 studies ${ }^{4,6,14,16,17,21}$ and RR from 5 studies $7,18,19,22,28$ were 0.92 (95\% CI, 0.62-1.23) and 1.01 (95\% CI, 0.44-2.34), respectively (Figure 5).

\section{Publication Bias}

There was no evidence of publication bias in the funnel plots of the primary or secondary outcomes. The Egger 
Study

RD valve: Intuity

Andreas et al, 2016

Borger et al, 2016

Bruno et al, 2016

Bening et al, 2017

Ferrari et al, 2017

Subtotal (I-squared $=0 \%, P=.763$ )

RD valve: Perceval S

D'Onofrio et al, 2013

Shretha et al, 2013

Gilmanov et al, 2014

König et al, 2014

Pollari et al, 2014

Muneretto et al, 2015

Dalén et al, 2016

Forcillo et al, 2016

Mataraci et al, 2016

Shalabi et al, 2016

Belluschi et al, 2017

Konert et al, 2017

Minami et al, 2017

Subtotal (l-squared=7.9\%, $P=.370$ )

RD valve: $3 f$ Enable or mixed

Vola et al, 2015

Smith et al, 2017

Subtotal (1-squared=0\%, $P=.599$ )

Overall (1-squared $=0 \%, P=.693$ ) $\begin{array}{cr}\text { RDAVR } & \text { CAVR } \\ \text { Events Total Events Total }\end{array}$

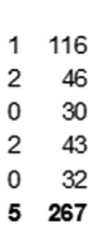

$5 \quad 267$

$\begin{array}{ll}0 & 31\end{array}$

$0 \quad 50$

1133

$0 \quad 14$

282

$12 \quad 204$

$\begin{array}{ll}3 & 171\end{array}$

$4 \quad 65$

$0 \quad 21$

$\begin{array}{ll}0 & 22\end{array}$

162

$0 \quad 16$

$0 \quad 52$

$23 \quad 923$

421113

$\begin{array}{llll}1 & 41 & 0 & 42 \\ 1 & 41 & 1 & 41 \\ \mathbf{2} & \mathbf{8 2} & \mathbf{1} & \mathbf{8 3}\end{array}$

301272

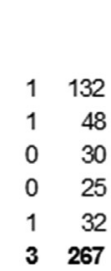

32
48
30
25
32
67
461463

Risk Ratio

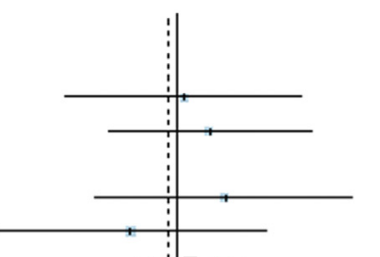

RR [95\% Cl]

$1.14(0.07,17.99)$

$2.09(0.20,22.24)$

$2.95(0.15,59.19)$

$0.33(0.01,7.89)$

$1.35(0.37,4.91)$

$1.18(0.05,28.20)$

$0.20 \quad(0.01,3.77)$

$0.50(0.05,5.45)$

$0.67 \quad(0.11,3.89)$

$1.71(0.69,4.27)$

$0.75(0.17,3.30)$

$0.80 \quad(0.26,2.45)$

$0.11(0.01,1.84)$

$0.14(0.02,1.13)$

$0.69(0.42,1.12)$

$3.07(0.13,73.29)$

$1.00(0.06,15.45)$

$1.69(0.23,12.45)$

$0.78(0.50,1.22)$

A

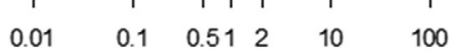

Favors RDAVR Favors CAVR

Risk Ratio

HR/RR [95\% CI]

HR

Shretha et al, 2013

Gilmanov et al, 2014

Pollari et al, 2014

Muneretto et al, 2015

Andreas et al, 2016

Dalén et al, 2016

Subtotal (I-squared $=0 \%, P=.853$ )

RR

Vola et al, 2015

Borger et al, 2016

Dedeilias et al, 2016

Ferrari et al, 2017

Minami et al, 2017

Subtotal (l-squared $=0 \%, P=.591$ )

Overall (1-squared $=0 \%, P=.902$ )

B

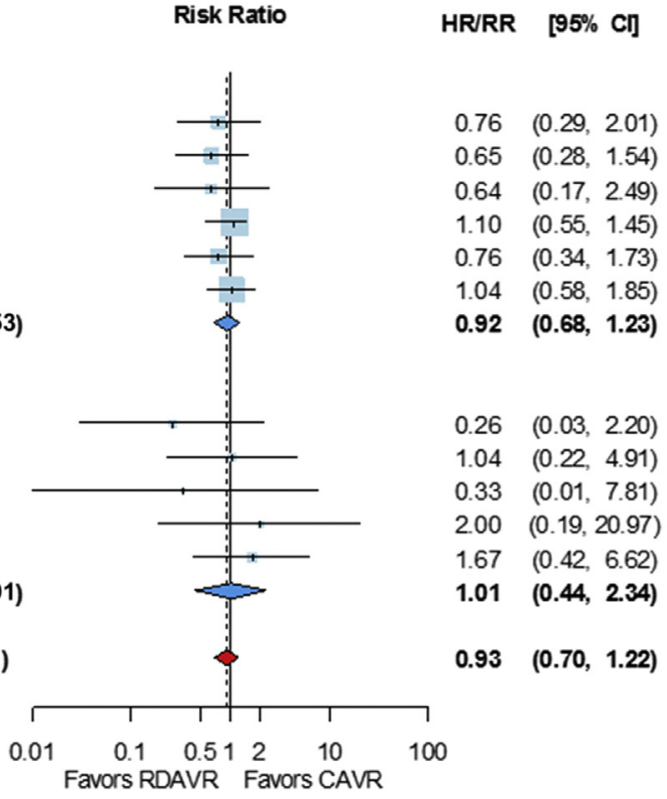

FIGURE 5. Risk ratio $(R R)$ of (A) early death and (B) hazard ratio $(H R)$ or RR of all-cause mortality during follow-up after rapid deployment or sutureless aortic valve replacement $(R D A V R)$ and conventional bioprosthetic aortic valve replacement $(C A V R)$. $C I$, Confidence interval; $R D$, rapid deployment. 
test also indicated that publication bias was nonsignificant for each outcome (Figure E4).

\section{DISCUSSION}

Our study showed 3 main findings. First, RDAVR resulted in overall reductions of 26 minutes and 25 minutes in the ACC and CPB times, respectively, compared with CAVR. Second, there were no differences in postoperative complications except for a higher risk of PPM implantation in the RDAVR group compared with the CAVR group. Third, early mortality and all-cause mortality during follow-up were similar between the 2 groups (Video 1).

One of the limitations related to RD valve insertion has been suggested to be a risk of PVL after surgery, and inadequate sizing and positioning are thought to be associated with PVL. ${ }^{18,31-33}$ Some surgeons have developed an aortic annular stabilization technique by performing circumferential aortic valve annuloplasty to adhere the annulus to the stent of the valve. ${ }^{33}$ Insufficient decalcification of the annulus can be another cause of PVL in RDAVR. ${ }^{34}$ The influence of PVL on late mortality is controversial. Some authors have insisted that PVL in RDAVR is mainly insignificant (grade 1 or mild) and thus has little influence on late mortality. ${ }^{19}$ In contrast, another study that presented the results of TAVR at 2 years suggested that even a mild degree of PVL could significantly worsen patient survival. ${ }^{35}$ In the present meta-analysis, when pooling data from the adjusted results, the risks of any PVL and a PVL grade $\geq 2$ did not significantly differ between the RDAVR and CAVR groups.

Another suggested limitation of RDAVR is its susceptibility to causing postoperative conduction disturbances that require PPM implantation. The left bundle branch (LBB) runs adjacent to the membranous septum, which is located at the base of the interleaflet triangle between the right and noncoronary cusps and the right fibrous trigone. In normal hearts, the valve leaflets are attached in a semilunar manner and therefore distant from the conduction pathway. However, in aortic stenosis conditions, the leaflets are fused, the valvular attachment approaches the ventriculoarterial junction, and the leaflet tissue moves close to the LBB. ${ }^{36}$ All RD valves are designed to sit below the level of the aortic annulus, which contrasts with conventional stented bioprostheses that are designed for supra- or intra-annular positioning; thus, RD valves might increase the possibility of conduction disturbances. A previous study reported that the depth of the prosthesis implantation was a strong predictor of new PPM implantation as well as new LBB blockage after TAVR. ${ }^{36}$ In addition to the prosthesis position, the outward force of the prosthesis has been suggested to be a contributory factor to conduction disturbances similar to TAVR valves. ${ }^{37,38}$ In the present study, the risk of PPM implantation after RDAVR was twofold greater than the
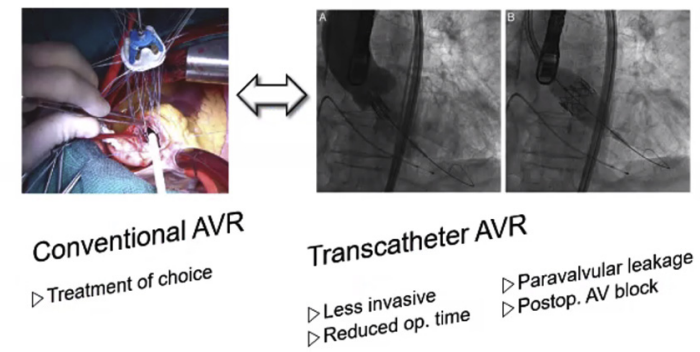

VIDEO 1. A presentation for meta-analysis of rapid deployment or sutureless versus conventional aortic valve replacement. Video available at: http://www.jtcvsonline.org/article/S0022-5223(18)30364-7/fulltext.

risk after CAVR. This result was consistent regardless of the RD valve type. Although sufficient evidence is not available regarding the influence of PPM implantation on late mortality, ${ }^{39,40}$ this issue could be a factor that offsets the benefits of RDAVR.

This meta-analysis presented the extent to which the ACC times could be reduced with RDAVR. Shortening the ACC time has been proven to be associated with better outcomes after cardiac surgery. ${ }^{30,31,41}$ A recent retrospective analysis of approximately 1000 patients who underwent surgical AVR showed that the ACC time was an independent predictor of cardiovascular morbidity after surgery with a $1.4 \%$ increase in the risk per minute of ACC time. ${ }^{42}$ In that study, the effect of a reduced ACC time was more relevant in high-risk patients, such as diabetic patients and those with left ventricular dysfunction. In the meta-analysis, the RDAVR group had a benefit of a 26-minute reduction in the ACC time. This decreased ACC time also resulted in a 25 -minute reduction in the CPB time. However, this benefit did not result in decreased risk in postoperative complications, early mortality, and all-cause mortality during follow-up in the present meta-analysis. A relatively low risk of surgical complications after AVR and a relatively short follow-up duration might explain these findings.

In addition to the shortening of the surgery time, another advantage of the use of RDAVR is that this technique can facilitate minimally invasive approaches. Although favorable outcomes after minimally invasive AVR were reported even before the era of RD valves, ${ }^{43-45}$ the limited exposure of the surgical field in minimally invasive AVR increases the technical complexity for the surgeons, which leads to longer ACC times. ${ }^{43,44}$ Therefore, the benefits derived from minimally invasive approaches could be offset by the prolongation of the ACC and CPB times. In the present study, minimally invasive approaches were used for $69.1 \%$ of the patients in the RDAVR group compared with only $37.7 \%$ of the patients in the CAVR group. When considering the surgeons' learning curves 
during their initial experiences with RD valves, improved early and long-term outcomes might be expected to accompany the advantages of minimally invasive approaches as well as shortening of the ACC and CPB times.

\section{Study Limitations}

Several limitations of this study should be recognized. First, only 2 of the 21 studies were RCTs. Although we separately showed results of pooled estimates from the adjusted analyses, confounding variables might have affected the results of our analysis. Second, the effect of learning curves on an institutional basis as well as for the individual training of surgeons could not be evaluated. Third, detailed information regarding aorta pathology and perivalvular involvement of disease, which might be important factors in determining the risk of PVL, could not be drawn from individual studies. Last, pooled analyses for the risks of postoperative complications were not drawn from all studies.

\section{CONCLUSIONS}

Aortic valve replacement with RD valves is associated with significantly shorter ACC and CPB times than conventional AVR, although these differences did not translate into improved postoperative complications and mortality early after surgery and during the follow-up. Care might be needed when implanting RD valves because they are associated with a higher incidence of PPM insertion, regardless of the $\mathrm{RD}$ valve type.

\section{Conflict of Interest Statement}

Authors have nothing to disclose with regard to commercial support.

The authors thank Dr Enrico Ferrari for confirming the data from his article via mail.

\section{References}

1. Nishimura RA, Otto CM, Bonow RO, Carabello BA, Erwin JP III, Guyton RA, et al. 2014 AHA/ACC guideline for the management of patients with valvular heart disease: executive summary: a report of the American College of Cardiology/American Heart Association task force on practice guidelines. Circulation. 2014;129:2440-92.

2. Smith CR, Leon MB, Mack MJ, Miller DC, Moses JW, Svensson LG, et al. Transcatheter versus surgical aortic-valve replacement in high-risk patients. $N$ Engl $J$ Med. 2011;364:2187-98.

3. Schlömicher M, Haldenwang PL, Moustafine V, Bechtel M, Strauch JT. Minimal access rapid deployment aortic valve replacement: initial single-center experience and 12-month outcomes. J Thorac Cardiovasc Surg. 2015;149:434-40.

4. Shrestha M, Höffler K, Koigeldiyev N, Marsch G, Siemeni T, Fleissner F, et al. Aortic valve replacement in geriatric patients with small aortic roots: are sutureless valves the future? Interact Cardiovasc Thorac Surg. 2013;17:778-83.

5. Shalabi A, Spiegelstein D, Sternik L, Feinberg MS, Kogan A, Levin S, et al. Sutureless versus stented valve in aortic valve replacement in patients with small annulus. Ann Thorac Surg. 2016;102:118-22.

6. Andreas M, Wallner S, Habertheuer A, Rath C, Schauperl M, Binder T, et al. Conventional versus rapid-deployment aortic valve replacement: a single- centre comparison between the Edwards Magna valve and its rapid-deploymen successor. Interact Cardiovasc Thorac Surg. 2016;22:799-805.

7. Ferrari E, Roduit C, Salamin P, Caporali E, Demertzis S, Tozzi P, et al. Rapiddeployment aortic valve replacement versus standard bioprosthesis implantation. J Card Surg. 2017;32:322-7.

8. Moher D, Liberati A, Tetzlaff J, Altman DG, PRISMA Group. Preferred reporting items for systematic reviews and meta-analyses: the PRISMA statement. Int J Surg. 2010;8:336-41.

9. Sterne JA, Hernán MA, Reeves BC, Savović J, Berkman ND, Viswanathan M, et al. Robins-I: a tool for assessing risk of bias in non-randomised studies of interventions. BMJ. 2016;355:i4919.

10. Wan X, Wang W, Liu J, Tong T. Estimating the sample mean and standard deviation from the sample size, median, range and/or interquartile range. $B M C$ Med Res Methodol. 2014;14:135.

11. Tierney JF, Stewart LA, Ghersi D, Burdett S, Sydes MR. Practical methods for incorporating summary time-to-event data into meta-analysis. Trials. 2007;8:16

12. Higgins JP, Thompson SG, Deeks JJ, Altman DG. Measuring inconsistency in meta-analyses. BMJ. 2003;327:557-60.

13. D’Onofrio A, Rizzoli G, Messina A, Alfieri O, Lorusso R, Salizzoni S, et al. Conventional surgery, sutureless valves, and transapical aortic valve replacement: what is the best option for patients with aortic valve stenosis? A multicenter, propensity-matched analysis. J Thorac Cardiovasc Surg. 2013;146:1065-71.

14. Gilmanov D, Miceli A, Ferrarini M, Farneti P, Murzi M, Solinas M, et al Aortic valve replacement through right anterior minithoracotomy: can sutureless technology improve clinical outcomes? Ann Thorac Surg. 2014;98 $1585-92$.

15. König KC, Wahlers T, Scherner M, Wippermann J. Sutureless Perceval aortic valve in comparison with the stented Carpentier-Edwards Perimount aortic valve. J Heart Valve Dis. 2014;23:253-8.

16. Pollari F, Santarpino G, Dell'Aquila AM, Gazdag L, Alnahas H, Vogt F, et al Better short-term outcome by using sutureless valves: a propensity-matched score analysis. Ann Thorac Surg. 2014;98:611-7.

17. Muneretto C, Alfieri O, Cesana BM, Bisleri G, De Bonis M, Di Bartolomeo R et al. A comparison of conventional surgery, transcatheter aortic valve replacement, and sutureless valves in "real-world" patients with aortic stenosis and intermediate- to high-risk profile. J Thorac Cardiovasc Surg. 2015;150:1570-9.

18. Vola M, Campisi S, Gerbay A, Fuzellier JF, Ayari I, Favre JP, et al. Sutureless prostheses and less invasive aortic valve replacement: just an issue of clamping time? Ann Thorac Surg. 2015;99:1518-23.

19. Borger MA, Dohmen PM, Knosalla C, Hammerschmidt R, Merk DR, Richter M et al. Haemodynamic benefits of rapid deployment aortic valve replacement via a minimally invasive approach: 1-year results of a prospective multicentre randomized controlled trial. Eur J Cardiothorac Surg. 2016;50:713-20.

20. Bruno P, Farina P, Cammertoni F, Biondi R, Perri G, Di Cesare A, et al. Miniaortic surgery with percutaneous cannulation and rapid-deployment valve. Asian Cardiovasc Thorac Ann. 2016;24:535-40.

21. Dalén M, Biancari F, Rubino AS, Santarpino G, Glaser N, De Praetere H, et al Aortic valve replacement through full sternotomy with a stented bioprosthesis versus minimally invasive sternotomy with a sutureless bioprosthesis. Eur J Cardiothorac Surg. 2016;49:220-7.

22. Dedeilias P, Baikoussis NG, Prappa E, Asvestas D, Argiriou M, Charitos C Aortic valve replacement in elderly with small aortic root and low body surface area; the Perceval S valve and its impact in effective orifice area. J Card Surg. 2016;11:54.

23. Forcillo J, Bouchard D, Nguyen A, Perrault L, Cartier R, Pellerin M, et al Perioperative outcomes with sutureless versus stented biological aortic valves in elderly persons. J Thorac Cardiovasc Surg. 2016;151:1629-36.

24. Mataraci I, Hanedan MO, Sayar U, Yürük MA, Özer T, Arslan AK, et al. Early outcomes of the sutureless aortic valves versus conventional stented bioprosthetic valves. Turk Gogus Kalp Dama. 2016;24:240-7.

25. Belluschi I, Moriggia S, Giacomini A, Del Forno B, Di Sanzo S, Blasio A, et al Can Perceval sutureless valve reduce the rate of patient-prosthesis mismatch? Eur J Cardiothorac Surg. 2017;51:1093-9.

26. Bening C, Hamouda K, Oezkur M, Schimmer C, Schade I, Gorski A, et al. Rapid deployment valve system shortens operative times for aortic valve replacement through right anterior minithoracotomy. J Cardiothorac Surg. 2017;12:27.

27. Konertz J, Zhigalov K, Weymann A, Dohmen PM. Initial experience with aortic valve replacement via a minimally invasive approach: a comparison of stented, stentless and sutureless valves. Med Sci Monit. 2017;23:1645-54.

28. Minami T, Sainte S, De Praetere H, Rega F, Flameng W, Verbrugghe P, et al Hospital cost savings and other advantages of sutureless vs stented 
aortic valves for intermediate-risk elderly patients. Surg Today. 2017;47: 1268-73.

29. Smith AL, Shi WY, Rosalion A, Yii M, O'Keefe M, Newcomb AE, et al. Rapid-deployment versus conventional bio-prosthetic aortic valve replacement. Heart Lung Circ. 2017;26:187-93.

30. Al-Sarraf N, Thalib L, Hughes A, Houlihan M, Tolan M, Young V, et al. Cross-clamp time is an independent predictor of mortality and morbidity in low- and high-risk cardiac patients. Int J Surg. 2011;9:104-9.

31. Englberger L, Carrel TP, Doss M, Sadowski J, Bartus K, Eckstein FF, et al. Clinical performance of a sutureless aortic bioprosthesis: five-year results of the $3 \mathrm{f}$ Enable long-term follow-up study. J Thorac Cardiovasc Surg. 2014;148:1681-7.

32. Folliguet TA, Laborde F, Zannis K, Ghorayeb G, Haverich A, Shrestha M Sutureless Perceval aortic valve replacement: results of two European centers. Ann Thorac Surg. 2012;93:1483-8.

33. Ferrari E, Siniscalchi G, Tozzi P, von Segesser LK. Aortic annulus stabilization technique for rapid deployment aortic valve replacement. Innovations (Phila). 2015;10:360-2.

34. Concistre G, Miceli A, Chiaramonti F, Glauber M. Delayed dislocation of a sutureless aortic bioprosthesis: the first case. Interact Cardiovasc Thorac Surg. 2012;14:892-3.

35. Kodali SK, Williams MR, Smith CR, Svensson LG, Webb JG, Makkar RR, et al. Two-year outcomes after transcatheter or surgical aortic-valve replacement. $N$ Engl J Med. 2012;366:1686-95.

36. Lenders GD, Collas V, Hernandez JM, Legrand V, Danenberg HD, den Heijer P, et al. Depth of valve implantation, conduction disturbances and pacemaker implantation with CoreValve and CoreValve Accutrak system for transcatheter aortic valve implantation, a multi-center study. Int J Cardiol. 2014;176:771-5.

37. Tracy CM. Pacemaker after transcatheter aortic valve replacement: unexpected, but not infrequent outcome. J Am Coll Cardiol. 2014;64:141-3.

38. Ledwoch J, Franke J, Gerckens U, Kuck KH, Linke A, Nickenig G, et al. Incidence and predictors of permanent pacemaker implantation following transcath- eter aortic valve implantation: analysis from the German transcatheter aortic valve interventions registry. Catheter Cardiovasc Interv. 2013;82:569-77.

39. Buellesfeld L, Stortecky S, Heg D, Hausen S, Mueller R, Wenaweser P, et al. Impact of permanent pacemaker implantation on clinical outcome among patients undergoing transcatheter aortic valve implantation. J Am Coll Cardiol. 2012;60:493-501.

40. Schymik G, Tzamalis P, Bramlage P, Heimeshoff M, Würth A, Wondraschek R, et al. Clinical impact of a new left bundle branch block following TAVR implantation: 1-year results of the TAVRK cohort. Clin Res Cardiol. 2015;104:351-62.

41. Doenst T, Borger MA, Weisel RD, Yau TM, Maganti M, Rao V. Relation between aortic cross-clamp time and mortality - not as straightforward as expected. Eur J Cardiothorac Surg. 2008;33:660-5.

42. Ranucci M, Frigiola A, Menicanti L, Castelvecchio S, de Vincentiis C, Pistuddi V. Aortic cross-clamp time, new prostheses, and outcome in aortic valve replacement. J Heart Valve Dis. 2012;21:732-9.

43. Barnhart GR, Accola KD, Grossi EA, Woo YJ, Mumtaz MA, Sabik JF, et al. TRANSFORM (multicenter experience with rapid deployment Edwards INTUITY valve system for aortic valve replacement) US clinical trial: performance of a rapid deployment aortic valve. J Thorac Cardiovasc Surg. 2017; $153: 241-51$

44. Brown ML, McKellar SH, Sundt TM, Schaff HV. Ministernotomy versus conventional sternotomy for aortic valve replacement: a systematic review and meta-analysis. J Thorac Cardiovasc Surg. 2009;137:670-9.

45. Laufer G, Wiedemann D, Chitwood WR Jr. Rapid-deployment valves: finally the fog is lifting-benefits beyond crossclamp and bypass times. J Thorac Cardiovasc Surg. 2017; 154:1527-31.

Key Words: rapid deployment, sutureless, aortic valve replacement, meta-analysis 


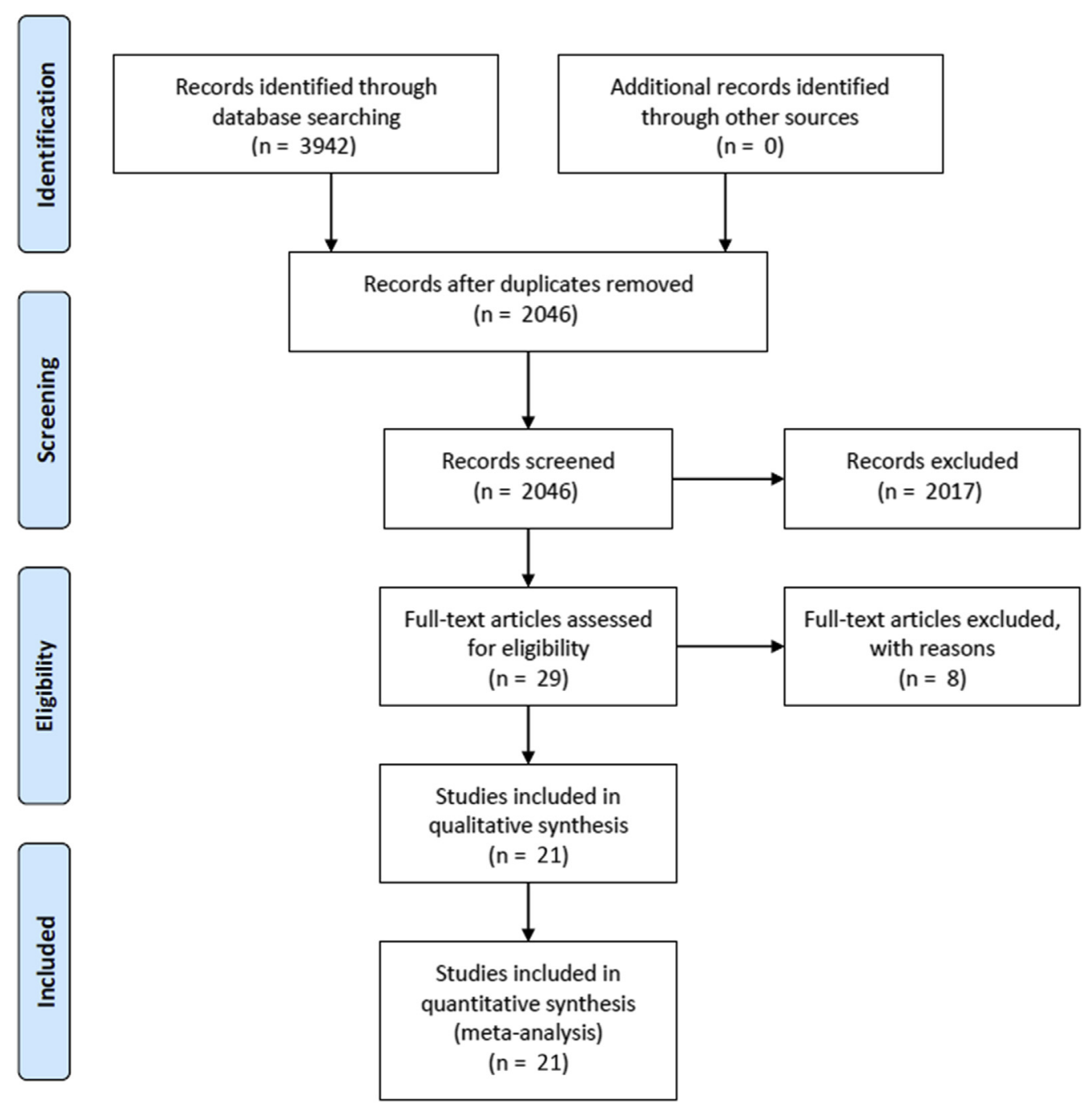

FIGURE E1. Preferred Reporting Items for Systematic Reviews and Meta-analyses flow diagram. 


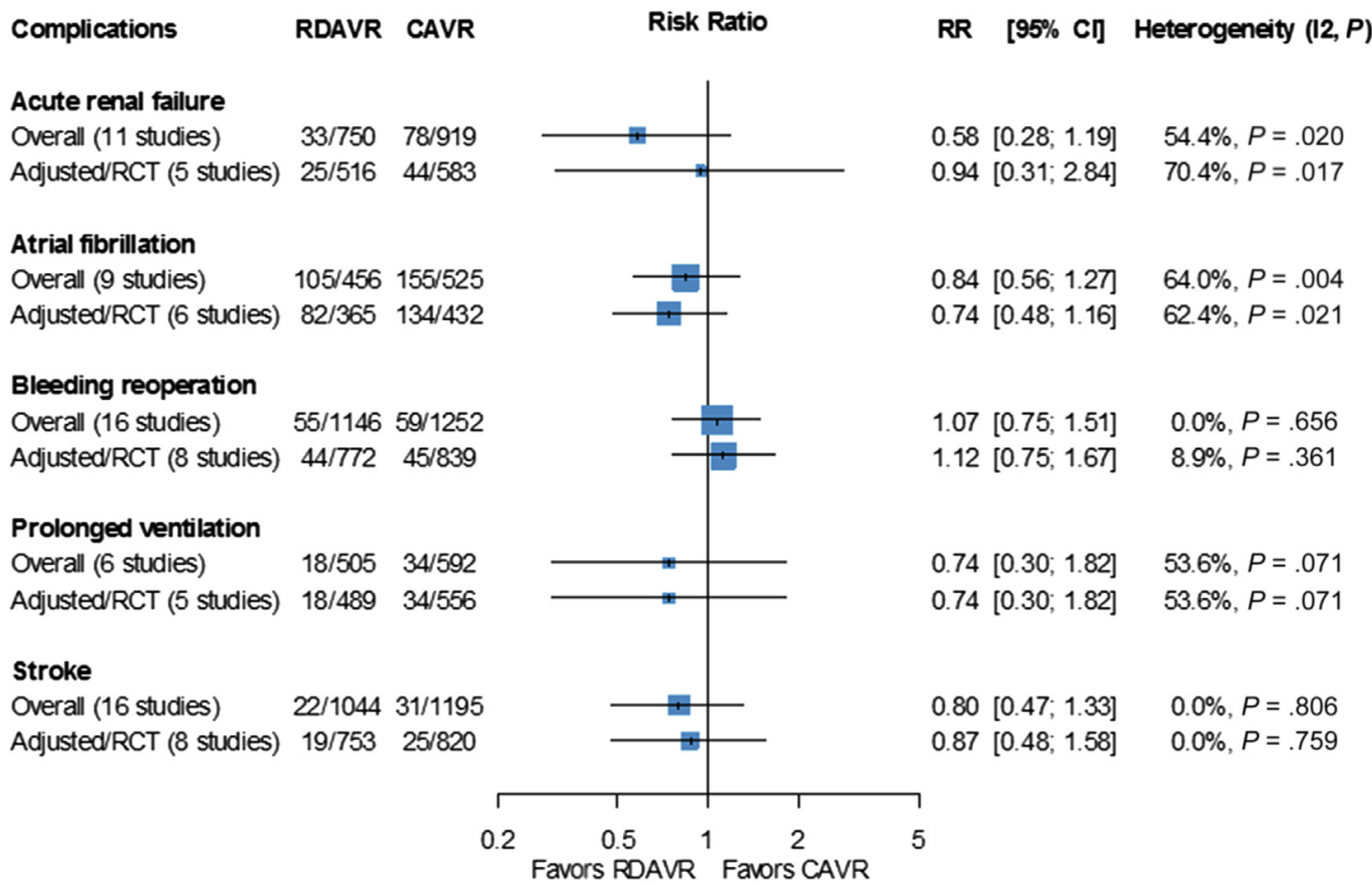

FIGURE E2. Risk ratio $(R R)$ of postoperative complications after rapid deployment or sutureless aortic valve replacement $(R D A V R)$ and conventional bioprosthetic aortic valve replacement $(C A V R)$. $C I$, Confidence interval; $R C T$, randomized controlled trial. 


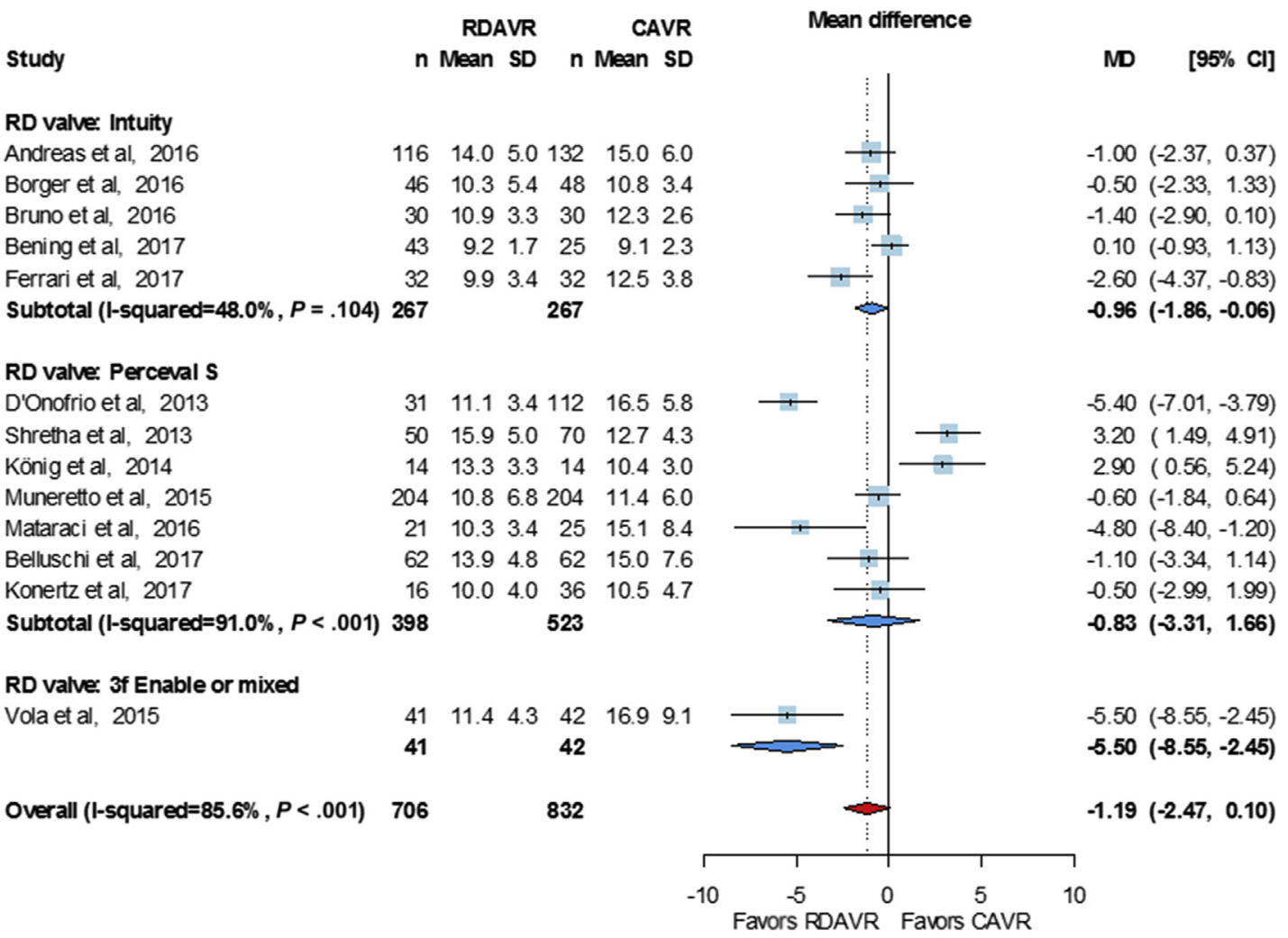

\section{RDAVR CAVR $\quad$ Mean difference}

Study

Muneretto et al, 2015

Borger et al, 2016

Bruno et al, 2016

\begin{tabular}{rrrrrrr}
\multicolumn{2}{c}{ n Mean SD } & \multicolumn{3}{c}{ n Mean SD } \\
204 & 10.8 & 6.8 & 204 & 11.4 & 6.0 \\
46 & 10.3 & 5.4 & 48 & 10.8 & 3.4 \\
30 & 10.9 & 3.3 & 30 & 12.3 & 2.6
\end{tabular}

Overall (1-5quared $=0.0 \%, P=.668) 280$

B
282

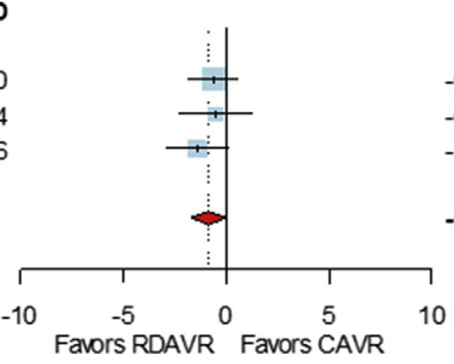

MD $[95 \%$ Cl $]$

$-0.60(-1.84,0.64)$

$-0.50(-2.33,1.33)$

$-1.40(-2.90,0.10)$

$-0.83(-1.68,0.02)$

FIGURE E3. Mean difference $(M D)$ of mean transvalvular pressure gradient after rapid deployment or sutureless aortic valve replacement $(R D A V R)$ and conventional bioprosthetic aortic valve replacement $(C A V R)(\mathrm{A})$ from overall studies and (B) from adjusted or randomized studies. $S D$, Standard deviation; $C I$, confidence interval; $R D$, rapid deployment. 

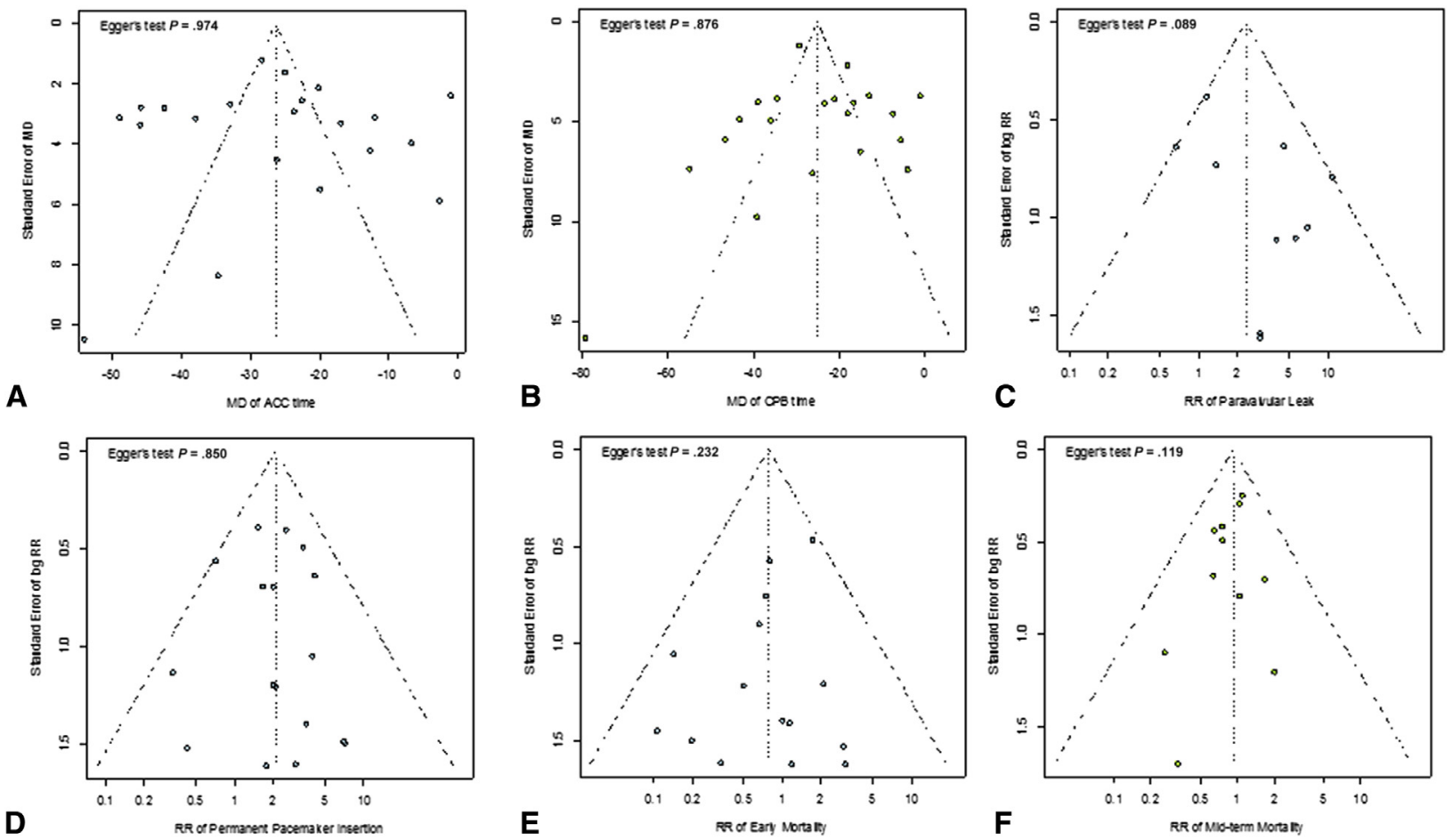

FIGURE E4. Funnel plots of standard error using log hazard ratio showing the effect of rapid deployment or sutureless aortic valve replacement and conventional bioprosthetic aortic valve replacement on mean differences (MDs) of (A) aortic cross clamp (ACC) and (B) cardiopulmonary bypass $(C P B)$ times, and risk ratios $(R R s)$ of $(\mathrm{C})$ paravalvular leak, (D) permanent pacemaker insertion, (E) early mortality, and (F) all-cause mortality during follow-up. 
TABLE E1. Quality assessment of included studies

\begin{tabular}{|c|c|c|c|c|c|c|c|c|}
\hline \multicolumn{9}{|c|}{ Quality assessment using Cochran Risk of Bias Tool for randomized controlled trials } \\
\hline & $\begin{array}{c}\text { Random } \\
\text { sequence } \\
\text { generation }\end{array}$ & $\begin{array}{c}\text { Allocation } \\
\text { concealment }\end{array}$ & $\begin{array}{c}\text { Blinding of } \\
\text { participants } \\
\text { personnel }\end{array}$ & $\begin{array}{c}\text { Blinding of } \\
\text { outcome } \\
\text { assessment }\end{array}$ & $\begin{array}{c}\text { Incomplete } \\
\text { outcome } \\
\text { data }\end{array}$ & $\begin{array}{l}\text { Selective } \\
\text { reporting }\end{array}$ & $\begin{array}{c}\text { Other } \\
\text { sources } \\
\text { of bias }\end{array}$ & Overall \\
\hline Borger et $\mathrm{al}^{19}$ & Unclear & Unclear & Unclear & Unclear & Low & Low & Low & Low \\
\hline Dedeilias et $\mathrm{al}^{22}$ & Low & Low & Unclear & Unclear & Low & Low & Low & Low \\
\hline \multicolumn{9}{|c|}{ Quality assessment according to Risk of Bias in Non-Randomized Studies of Interventions for nonrandomized studies } \\
\hline Study & $\begin{array}{l}\text { Bias due to } \\
\text { confounding }\end{array}$ & $\begin{array}{c}\text { Bias in } \\
\text { selection of } \\
\text { participants } \\
\text { into the study }\end{array}$ & $\begin{array}{c}\text { Bias in } \\
\text { measurement } \\
\text { of interventions }\end{array}$ & $\begin{array}{c}\text { Bias due to } \\
\text { departures from } \\
\text { intended } \\
\text { interventions }\end{array}$ & $\begin{array}{c}\text { Bias due } \\
\text { to missing } \\
\text { data }\end{array}$ & $\begin{array}{c}\text { Bias in } \\
\text { measurement } \\
\text { of outcomes }\end{array}$ & $\begin{array}{l}\text { Bias in } \\
\text { selection of the } \\
\text { reported result }\end{array}$ & Overall \\
\hline${\text { D’Onofrio et } a l^{13}}^{13}$ & Serious & Low & Low & Low & Low & Low & Low & Serious \\
\hline Shretha et $\mathrm{al}^{4}$ & Serious & Low & Low & Low & Low & Low & Low & Serious \\
\hline Gilmanov et al ${ }^{14}$ & Moderate & Low & Low & Low & Low & Low & Low & Moderate \\
\hline König et $\mathrm{al}^{15}$ & Serious & Low & Low & Low & Low & Low & Low & Serious \\
\hline Pollari et al ${ }^{16}$ & Moderate & Low & Low & Low & Low & Low & Low & Moderate \\
\hline Muneretto et al ${ }^{17}$ & Moderate & Low & Low & Low & Low & Low & Low & Moderate \\
\hline Vola et $\mathrm{al}^{18}$ & Serious & Low & Low & Low & Low & Low & Low & Serious \\
\hline Andreas et $\mathrm{al}^{6}$ & Serious & Low & Low & Low & Low & Low & Low & Serious \\
\hline Bruno et $\mathrm{al}^{20}$ & Moderate & Low & Low & Low & Low & Low & Low & Moderate \\
\hline Dalén et $\mathrm{al}^{21}$ & Moderate & Low & Low & Low & Low & Low & Low & Moderate \\
\hline Forcillo et $\mathrm{al}^{23}$ & Moderate & Low & Low & Low & Low & Low & Low & Moderate \\
\hline Mataraci et $\mathrm{al}^{24}$ & Serious & Low & Low & Low & Low & Low & Low & Serious \\
\hline Shalabi et $\mathrm{al}^{5}$ & Moderate & Low & Low & Low & Low & Low & Low & Moderate \\
\hline Belluschi et $\mathrm{al}^{25}$ & Serious & Low & Low & Low & Low & Low & Low & Serious \\
\hline Bening et $\mathrm{al}^{26}$ & Serious & Low & Low & Low & Low & Low & Low & Serious \\
\hline Ferrari et $\mathrm{al}^{7}$ & Serious & Low & Low & Low & Low & Low & Low & Serious \\
\hline Konertz et $\mathrm{al}^{27}$ & Serious & Low & Low & Low & Low & Low & Low & Serious \\
\hline Minami et $\mathrm{al}^{28}$ & Serious & Low & Low & Low & Low & Low & Low & Serious \\
\hline Smith et $\mathrm{al}^{29}$ & Moderate & Low & Low & Low & Low & Low & Low & Moderate \\
\hline
\end{tabular}

